\title{
Exploring the Application of Traditional Elements in Cultural and Creative Product Design
}

\author{
Jun Zhang \\ Department of Film and Television Arts, Shanghai Publishing and Printing College, Shanghai, China \\ Email: cllapse@126.com
}

How to cite this paper: Zhang, J. (2021). Exploring the Application of Traditional Elements in Cultural and Creative Product Design. Art and Design Review, 9, 332-340. https://doi.org/10.4236/adr.2021.94029

Received: October 21, 2021

Accepted: November 26, 2021

Published: November 29, 2021

Copyright $\odot 2021$ by author(s) and Scientific Research Publishing Inc. This work is licensed under the Creative Commons Attribution International License (CC BY 4.0).

http://creativecommons.org/licenses/by/4.0/

\begin{abstract}
With the rapid development of social economy and the improvement of people's standard, the development of cultural and creative products has ushered in spring. In order to improve the competitiveness and enhance the economic value of cultural and creative products, designers need to change their design concepts and innovate the design methods, application fields, and design depth of traditional elements in order to expand the consumer market of cultural and creative products. By increasing the use of traditional elements, the artistic image of cultural and creative products will be continuously enriched to meet the growing cultural needs of people. The paper analyzes the relationship between Chinese traditional elements and cultural and creative product design, explains the principles that need to be followed in the design of cultural and creative products, proposes three scientific design methods, and demonstrates how to combine Chinese traditional elements with cultural and creative products, and use traditional elements as an important source for the development of cultural and creative industries to form creative products with Chinese elements.
\end{abstract}

\section{Keywords}

Cultural and Creative Products, Traditional Elements, Designers

\section{Introduction}

China is a country of ancient civilization with a long history, and the cultural genes accumulated over the years consist of various forms of traditional elements. Cultural and creative industries are closely related to traditional culture and are an important direction for the development of China's cultural soft power. Cul- 
tural and creative products belong to the category of cultural and creative industries. Referring to the definition of UNESCO, cultural and creative industries are composed of cultural products, cultural services and intelligent property rights (Yang, 2019). These creative products are usually rich in specific cultural connotations and symbolic meanings, as well as uniqueness and differentiation (Jiang \& Wang, 2006). With the help of the law of formal beauty, designers interpret and analyze the concept in cultural dimension, and transform the concept into cultural and creative products that conform to modern life and have certain practical functions ( $\mathrm{Lu} \&$ Z Zhao, 2016). In the process of materializing traditional elements, traditional culture will gain new values and connotations, giving our cultural and creative products more possibilities.

\section{Connotation of Cultural and Creative Products}

\section{1) Concept of cultural and creative products}

Literally analyzed, cultural and creative products embody two core essential connotations. One is cultural creativity, and the other is product effect and the added value of the product. Based on China's 5000 years of cultural history, Chinese cultural and creative products have extremely rich connotations and can accommodate more cultural imagery. Therefore, to make cultural and creative products more artistic and effective, it is necessary to add their cultural and creative elements and optimize their cultural and creative contents, so as to meet people's growing sense of creativity. In addition, in order to realize the product effect, it is also necessary to increase the development of products and property rights, and continuously sublimate the cultural value that the products bring with them, so that people are more willing to consume cultural and creative products, and experience and feel the beauty of life from them (Xu, 2019).

\section{2) Development of cultural and creative products}

With the development of science and technology in the $21^{\text {st }}$ century and the improvement of people's material and spiritual quality of life, cultural and creative products have been given many opportunities for development. Under the influence of this background, the proportion of cultural and creative products in the total consumption products increases year by year, making the market of cultural and creative products more prosperous (Jiang, 2016). On some level, cultural and creative products are about creative methods. A good cultural and creative product is often extremely creative and practical. By spreading its essential connotation elements and continuously enriching its knowledge heritage, the added value of cultural and creative products is optimized, so that people will willingly consume its cultural value while accepting the connotation of cultural and creative products' ideas.

\section{Principles to Be Followed in Designing Cultural and Creative Products}

Creative product design is different from traditional artwork design in that it focuses on the unity of artistry and aesthetics, while taking into account the 
principle of practicality. Traditional artwork design is subject to personal preferences, materials, styles, and use scenarios, and usually appears in the form of handicrafts that are more decorative and less practical, such as paintings, clay sculptures, carvings, paper art, embroidery works, etc (Gao, 2016). The cultural and creative products incorporating traditional elements transform into common objects in daily life, integrating aesthetic interest, artistic expression, national heritage and practicality. Therefore, the design of cultural and creative products needs to comply with the following principles.

\section{1) Principles of aesthetic}

With the development of the economy and the improvement of people's ideology, the concept of aesthetics has changed drastically. Under the influence of traditional cultural consciousness, people only consider whether the goods have practical functions and whether they can bring more direct benefits to people's life. With the improvement of living standards and aesthetic concepts, people have developed higher requirements for objects. From the previous functionality of the items, they have expanded to artistry, aesthetics and connotation, and the development route of cultural and creative products has begun to change fundamentally. In order to improve the design ability of cultural and creative products, designers must follow the principle of aesthetics. In the actual design process, designers should start from the perspective of popularization, and should focus on highlighting the beauty of products and enhancing the beauty of product image and inner beauty, so that people can immerse themselves in the charm of cultural and creative products and experience the joy brought by aesthetics.

\section{2) Principle of inheritance}

In the actual design of cultural and creative products, it is very important to adhere to the principle of inheritance. It is directly related to the quality of the development of cultural and creative ideas and the comprehensive embodiment of product value. If the creative ideas of the cultural and creative products are not well inherited, it is easy to make the product design lose its soul and reduce the cultural image of the cultural and creative products, thus making the road of development of the cultural and creative products become narrower and narrower. Based on this, in order to enable the cultural and creative products to seize more markets, it is necessary to inherit their cultural penetration, humanistic sentiment expression methods, etc., so as to enhance the social status of the cultural and creative products and improve their popularity.

\section{3) Principle of practicality}

On some level, the design of any product needs to follow the principle of practicality. Deviating from the principle of practicality will make people lose the desire to use it. Even if the product design has more creative elements and gains people's favor, it will not meet people's essential needs of using the product, which will cause the connotation image of the product to decline and the value of the product to fall. In the long run, cultural and creative products can only 
meet people's psychological demands, but lose their own physiological functions, thus appearing many aspects of deficiencies and defects. Based on this, designers should start from actual life, constantly meet the requirements of the application of the principle of practicality, and constantly highlight the vitality of the product itself.

\section{The Use of Traditional Elements in the Design of Cultural and Creative Products}

Using the above three principles, the author proposes several design methods that integrate traditional elements to expand the outreach of thinking in the process of designing cultural and creative products (Ge, 2018). The three areas of Chinese ink and calligraphy, traditional festivals, and myths and legends are discussed separately, detailing the methods and guidelines for the application of traditional elements in the design of cultural and creative products.

1) Relying on the elements of Chinese ink and calligraphy to improve the comprehensive literacy of cultural and creative products

Generally speaking, traditional elements are of various kinds and have their own characteristics. Especially, the embodiment of cultural value of each element is also very prominent. In order to improve the comprehensive literacy of cultural and creative products, designers need to use the art of Chinese ink and calligraphy in the actual design process to continuously improve the image of cultural and creative products, so as to enhance the artistic sense of cultural and creative products. First, designers need to correctly cognize the elements of Chinese ink and calligraphy. By strengthening the application of Chinese ink and calligraphy elements, the cultural atmosphere with more visual effect can be perfectly permeated in the whole cultural and creative product design, thus giving people a refreshing artistic impact. Second, designers should pay attention to enhancing the excavation of Chinese ink and calligraphy elements. By displaying the colors of Chinese ink and the shape and soul of calligraphy, they constantly introduce people to a more stripped-down and elegant artistic environment, thus promoting people's perception of the aesthetic value of cultural and creative products. Finally, in product design, designers need to start from actuality as well as combine local characteristics to continuously put a vivid coat on cultural and creative products and continuously optimize a more effective artistic mind to promote cultural and creative products to step into a new artistic realm and better guide people's spiritual life.

2) Using traditional festivals, landscapes and other elements to enhance the characteristics of cultural and creative products

As we all know, traced the history of Chinese cultural development, it is easy to see that Chinese culture has gone through a long time of precipitation, which not only demonstrates the artistic wisdom of the ancestors, but also achieves more profound artistic attainments. In the actual cultural and creative products, designers follow the principles of aesthetics, inheritance and practicality to con- 
stantly plan the development direction of cultural and creative products. Through more frequent use of traditional elements, the artistic connotation of cultural and creative products is constantly enhanced, so that people can feel a stronger cultural atmosphere and enhance their cultural and artistic taste. First, in the actual product design, designers can combine some traditional festival contents to enrich the artistic image of the whole product. For example, designers can combine China's most famous traditional festival, the Spring Festival, and constantly apply a variety of happy images in the Spring Festival, as the theme content of product design, so that people can find their own happiness in the process of aesthetic products. Second, in the actual product design, designers need to pay attention to the use of landscape and other elements. From ancient times to the present, the Chinese have expressed their emotions mostly by means of subtle expressions, and borrowing scenery to express emotions is a common technique for expressing emotions. Based on this, designers can search for more and better landscape resources to continuously show the artistic charm of cultural and creative products, so that the products and landscape elements can be organically integrated together to show the characteristics of Chinese cultural and creative products. For example, designers can search for some famous Chinese royal scenery, such as the Forbidden City, and also search for some ancient folk people's clothing, etc. To continuously improve the core literacy of cultural and creative products, so as to create a cultural atmosphere for people and enhance the artistic character of cultural and creative products. Figure 1 shows an USB flash disk shell designed and made with traditional shadow play pattern elements.

3) Using mythological story elements to improve the image power of cultural and creative products

Compared with Western mythology, Chinese mythology has a more obvious integrity. In traditional culture, there are many mythological stories passed down in China, such as Jingwei Fills up the Sea, Kuafu Chasing the Sun, the Foolish Old Man Who Removes a Mountain, etc., which all reflect the unique qualities of ancient Chinese people such as perseverance, boldness and persistence. By infiltrating the elements of mythological stories into the creation of cultural and



Figure 1. USB flash disk shell designed and made with traditional shadow play pattern elements. 
creative products, the tension of the products themselves can be better demonstrated. Therefore, in order to improve the image power of creative products, designers need to increase the application of mythological elements. First, designers need to organize Chinese mythological stories. By integrating the classic myths and legends, they can continuously enhance their contents and manifest their will, thus improving the influence of traditional Chinese culture while enhancing the artistic taste of the whole cultural and creative products. For example, designers can enrich the artistic image of "the Goddess Mending the Sky". By showing the purpose, content and result of Goddess mending the sky, the artistic charm of Goddess mending the sky is constantly highlighted, and the core value of the cultural and creative products is constantly enhanced. Second, designers need to render the atmosphere of the mythological stories. By grafting the content of mythological stories into the design of cultural and creative products, the ideological pattern of cultural and creative products is constantly broadened. For example, in the actual design, designers need to combine people's thoughts and emotions to portray a complete mythological story image. By expressing the central idea of the mythological story, the character of culture and art is constantly enhanced, as well as sublimating the effect of culture and art. Figure 2 shows a decorative plate designed and made with the fairy tale "Nu Wa Mends the Sky" in the Classic of Mountains and Seas.

\section{Thoughts on the Application of Traditional Elements in Cultural and Creative Product Design}

\section{1) Modularize the design to enhance the design effect}

Generally speaking, to optimize the design of cultural and creative products, it is necessary to pay attention to the ways and means. Find the entry point of product design in terms of connotation creativity and the demand point of product design in terms of form and style in order to meet the path development of cultural and creative products at the maximum. Therefore, systematizing and

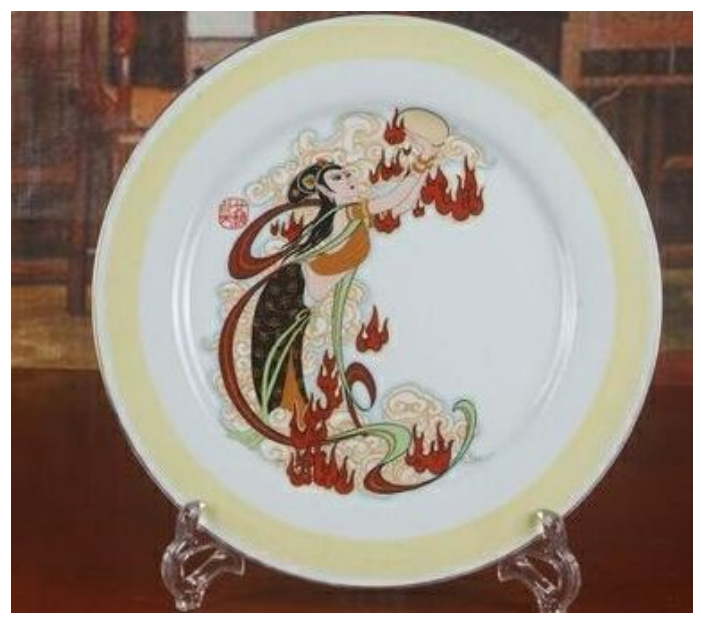

Figure 2. Decorative plate designed and made with the fairy tale "Nu Wa Mends the Sky" in the Classic of Mountains and Seas. 
modularizing the design is a scientific means to enhance the effect of cultural and creative product design. First, designers need to pay attention to the starting point of product design. By clarifying the ideological theme to be portrayed by the product and constantly looking for the corresponding traditional elements, the connotation of the product can be enhanced to the maximum extent, avoiding a sense of incongruity between the idea and the form of the product. Second, designers need to pay attention to enhancing the brand effect of cultural and creative products. By standardizing the design direction, deepening the design content, and continuously realizing the reorganization of elemental units with the help of various reliable design elements, they can create more novel and characteristic cultural and creative products. Finally, designers should pay attention to developing design ideas, continuously integrating traditional elements, and continuously innovating design methods, so as to reduce product creation costs and improve product creation efficiency at the same time. In order to make product design more distinctive, designers can take the path of simplifying and diversifying elements. In the simplification of elements, designers can simplify the number of traditional elements and strengthen the construction of simplified elements. In terms of element diversification, designers can use as many traditional elements of different styles as possible in the product design, so as to show a more profound and rich artistic meaning of the product.

2) Beautify the product image and enhance the design connotation

On some level, beautifying the product image is an effective means to enhance the design connotation and a direct way to improve the quality of product character. In order to realize the effective development of cultural and creative products, designers need to beautify the product shape, so as to gradually strengthen the creative effect and beautify the function. First of all, designers need to consider the artistic soul of the product itself, consumer thinking and other factors, and constantly look for ways and means to improve product quality in terms of creativity and aesthetics. Generally speaking, in terms of creativity, designers only need to increase the use of traditional elements to achieve the connotation of the design towards the pinch. But in terms of aesthetics, designers need to pay attention to both physiological and psychological changes of consumers. By blossoming the connotation of the product and sublimating the artistic image of the product, the product is constantly made public in an alternative shape, thus creating a more influential image of cultural and creative products. Secondly, designers should pay attention to the application of various patterns that contain rich content. For example, designers can incorporate some patterns of flowers and birds into the product design, so that the product can show more artistic features and introduce consumers to the scene of "birds' twitter and fragrance of flowers", and promote consumers to experience and perceive nature.

3) Divergent design thinking and expand design ideas

With the development of the creative product design industry, the traditional design methods can no longer meet people's needs. In order to improve the 
quality of cultural and creative product design, designers must divergent their thinking and broaden their design ideas. By creating more visual element symbols and displaying more unique artistic aesthetics, they can find a way out for the survival and operation of cultural and creative products in the context of the development of the new era. First of all, designers should increase their learning efforts, constantly purify their own minds and precipitate their own knowledge, so as to inspire and use the thinking of integrating the past and the present to design more thoughtful and representative cultural and creative products. Secondly, designers should pay attention to optimizing design creativity and enhancing design aesthetics. By sublimating the connotation of cultural and creative products and deepening the character of oriental art, they should continue to take creative design as the core and improve the design aesthetics comprehensively to promote the organic development of cultural and creative products. Finally, designers should pay attention to studying the various elements needed for design, such as aesthetics and livability (Yi, 2018). By creating an aesthetic external image and a profound internal temperament, the artistic charm of cultural and creative products is constantly improved and the spirit of traditional culture is constantly deepened, so that cultural and creative products can face the world in a high profile and promote the steady and orderly development of cultural and creative industries.

\section{Conclusion}

Creativity comes from culture and is enriched with traditional cultural elements. To design excellent cultural and creative products, we should explore traditional culture, follow the development of the times, integrate traditional elements into the design of cultural and creative products, and promote traditional culture in them. Therefore, we can experience the cultural connotations therein, create sustainable designs, and continuously improve the level of cultural and creative industries.

In the context of the development in the cultural and creative era, improving the quality and connotation of cultural and creative products has become an issue that every designer needs to pay attention to (Yang, 2017). Designers should actively use traditional Chinese elements, apply creative principles scientifically and rationally, and continuously increase their own creative design ability, so that cultural and creative products can be developed in inheritance, then continue the spirit of Chinese traditional culture and improve the development momentum of cultural and creative industry.

\section{Fund Support}

The research is funded by the Higher Education Research Institute of Shanghai Publishing and Printing College.

\section{Conflicts of Interest}

The author declares no conflicts of interest regarding the publication of this paper. 


\section{References}

Gao, Y. (2016). Research on the Application of Yangzhou Non-Heritage Culture in Cultural and Creative Product Design. East China University of Science and Technology.

Ge, C. (2018). Demand Analysis and Transformation in the Process of Cultural and Creative Product Design. Decoration, 2, 142-143.

Jiang, L. (2016). The Application of Traditional Elements in the Design of Cultural and Creative Products. Industrial Design, 12, 127.

Jiang, S., \& Wang, X. (2006). Research on Cultural and Creative Industries. Capital University of Economics and Trade Press.

Lu, H. L., \& Zhao, C. (2016). Explore Taiwan's Cultural and Creative Industry Thinking on the Cultural and Creative Industry in Southern Jiangsu. Art Science and Technology.

$\mathrm{Xu}$, S. S. (2019). Application of Traditional Elements in Cultural and Creative Product Design. Drama House, 8, 107-108.

Yang, H. (2019). An Analysis of the Application of Traditional Elements in the Design of Cultural and Creative Products. Art Science and Technology, 32, 221.

Yang, H. Z. (2017). Intangible Cultural Heritage and Cultural Creative Product Design. China Academy of Art.

Yi, P. (2018). Museum Cultural and Creative Product Design in the Context of Cultural Consumption. Packaging Engineering, 8, 84-88. 